\title{
ASPECTOS POLÊMICOS DO ACORDO DE LENIÊNCIA
}

\author{
Mayara Souza de Oliveira, João Paulo A. Vasconcelos
}

Universidade do Oeste Paulista - UNOESTE, curso de Direito, Presidente Prudente, SP. E-mail: mayara unesp@hotmail.com

\section{RESUMO}

O acordo de leniência é concedido pelo Conselho Administrativo de Defesa Econômica (CADE), por decisão administrativa. A celebração do acordo tem o condão de afastar penalidades administrativas e a punibilidade de crimes contra a ordem econômica. Em razão das imunidades concedidas, surgem indagações acerca da constitucionalidade do instituto e da possibilidade da revisão desta decisão pelo Poder Judiciário. O presente artigo tem como objetivo o estudo do acordo de leniência e as polêmicas referentes à sua aplicação no combate aos cartéis. A metodologia constou de pesquisas bibliográficas, os dados obtidos foram analisados utilizando-se do método hipotético dedutivo. Com a presente pesquisa constatou-se que a aplicação do instituto é uma arma contemporânea indispensável no combate aos cartéis. Conclui-se que a celebração do acordo colabora diretamente com o equilíbrio do mercado, tutelando o direito a uma concorrência equilibrada, com preços competitivos, o que justifica sua aplicação e as imunidades concedidas.

Palavras-chave: Lei antitruste. Leniência. CADE.

\section{CONTROVERSIAL ASPECTS OF THE LENIENCY AGREEMENT}

\begin{abstract}
The leniency agreement is awarded by the Administrative Council of Economic Defense (CADE), by administrative decision. The signing of the agreement has the effect of removing administrative penalties and criminal liability for crimes against economic order. On account of the immunities granted questions arise about the institute's constitutionality and the possibility for review this decision by the judiciary. This article aims to study the leniency agreement and the controversies relating to its application in the fight against cartels. The methodology consisted of bibliographic research, the data were analyzed using the hypothetical deductive method. With this research it was found that the application of the institute is an indispensable contemporary weapon in the fight against cartels. It concludes that the agreement reached collaborates directly with the market balance, tutoring the right to fair competition, competitive prices, justifying their application and immunities granted.
\end{abstract}

Keywords: Antitrust law. Leniency . CADE 


\section{INTRODUÇÃO}

A Lei $n^{\circ}$ 12.529/2011, denominada de Lei Antitruste, em seu art. 36, prevê que a infração da ordem econômica ficará caracterizada por atos que objetivem limitar, falsear ou prejudicar a livre concorrência ou a livre-iniciativa, dominar mercado relevante, aumentar os lucros de forma arbitrária ou exercer de forma abusiva posição dominante, independentemente de culpa ou de êxito. O cartel é caracterizado pelo acordo entre empresas concorrentes, que atuam no mesmo mercado relevante, com a finalidade de neutralizar a concorrência, manipular preços ou dividir mercados e consumidores.

Como forma de combate aos cartéis foi inserido na Lei $n^{\circ}$ 8. 884/94 o acordo de leniência, que tem como objetivo reprimir e punir a formação de cartéis. Para isso oferece isenção ou redução de pena para o integrante que delatar o cartel. A Lei Antitruste atual manteve a mesma figura. No entanto, algumas questões se levantam acerca da constitucionalidade do instituto, da discricionariedade para concessão do acordo de leniência e da possibilidade de revisão da concessão pelo Judiciário, haja vista que se trata de decisão administrativa.

O escopo deste artigo é abordar os aspectos polêmicos que cercam o instituto do acordo de leniência, bem como apresentar a discussão doutrinária a respeito do tema proposto.

\section{METODOLOGIA}

O artigo foi embasado em pesquisas bibliográficas, leituras, bem como em leis, resoluções e artigos eletrônicos. Os dados foram examinados com a aplicação do método hipotético-dedutivo, isto é, partindo do geral para o particular e as informações coletadas analisadas e confrontadas de forma dialética.

\section{DISCUSSÃO}

O acordo de leniência permite que um participante do cartel ou de outra conduta restritiva da concorrência denuncie a prática à autoridade antitruste, colaborando com as investigações e, em contrapartida, receba imunidade administrativa e criminal, ou a redução das penalidades aplicadas às práticas anticoncorrenciais (BRASIL. CADE, 2015, p. 1).

Dessa forma, o acordo de leniência caracteriza-se como importante instrumento das autoridades antitruste no combate aos cartéis, tendo em vista que seus participantes, a cada dia, criam novas formas de tornar o acordo mais sigiloso, pois conhecem a ilicitude de sua conduta. Dessa forma, os meios convencionais para obtenção de provas, como a busca e apreensão, podem não ser eficazes para obtenção de informações relevantes que possam embasar o procedimento 
administrativo.

Para celebração do acordo de leniência e obtenção das imunidades oferecidas aos delatores é necessário o preenchimento de requisitos estabelecidos pela Lei Antitruste. 0 artigo 86 da Lei 12.529 de 2011 prevê que "o CADE, por intermédio da Superintendência-Geral, poderá celebrar acordo de leniência" (BRASIL, C.N, 2011, p. 1). O acordo poderá ser celebrado com pessoas físicas ou jurídicas autoras de infração da ordem econômica, desde que a colaboração seja efetiva e resulte em uma das hipóteses previstas nos incisos do artigo 86, são elas: identificação dos outros envolvidos e a obtenção de documentos que comprovem a existência do crime noticiado pelo delator ou que seja objeto de investigação.

Para celebração do acordo é necessário que: I-) a empresa seja a primeira a celebrá-lo; II-) a cessação completa do envolvimento da empresa delatora na prática do ilícito, a partir da celebração do acordo; III-) a inexistência de provas suficientes em poder da SuperintendênciaGeral para condenação das empresas envolvidas no ilícito ao tempo da solenização do acordo; IV-) e, a confissão e cooperação plena por parte da empresa que tenha firmado o acordo, comparecendo a suas custas, sempre que requisitada, a todos os atos processuais, até a sua extinção. Esses requisitos são cumulativos, não basta apenas o cumprimento de um deles ou de alguns para obtenção do benefício, com exceção das pessoas físicas que para celebrarem o acordo deverão cumprir os requisitos II, III e IV (BRASIL, C.N, 2011, p. 1).

O Tribunal após o julgamento do processo administrativo, verificando o cumprimento do acordo, concederá o privilégio decorrente do acordo de leniência, que segundo o $\S 4^{\circ}$, inciso I, do artigo 86 da Lei Antitruste, será a decretação da extinção da ação punitiva em favor do delator, quando as provas apresentadas à Superintendência-Geral, por meio do acordo de leniência, digam respeito à infração não conhecida pela autoridade antitruste. Nas demais hipóteses a pena será reduzida de 1 (um) a 2/3 (dois terços).

Não obstante os benefícios do acordo de leniência, e sua importância para manutenção de um mercado equilibrado, pautado na concorrência lícita entre seus agentes, há certo questionamento a respeito da sua constitucionalidade, pois a prática de cartel é tipificada como crime e as isenções oferecidas pelo acordo de leniência alcançariam a orbita penal. Deste modo, tendo em vista que o acordo é celebrado entre a autoridade administrativa - CADE e o participante do cartel, sem intervenção do Judiciário, que é exclusivamente competente para exercer a jurisdição em matéria criminal, haveria afronta ao disposto no artigo $5^{\circ}$, inciso LII, do Constituição Federal (GABAN, DOMINGUES, 2011, p. 297).

Lima e Acqua (2007, s.p.) entendem ser inconstitucional o acordo de leniência, em razão de 
a decisão ser tomada exclusivamente pelo órgão administrativo, que analisa as provas, define o crime cometido, e identifica os coautores e, por fim, extingue ou não a punibilidade, o que ofenderia o princípio da reserva de jurisdição previsto no artigo $5^{\circ}$ da Constituição Federal, e por afrontá-la, não deveria ser atribuído nenhum efeito ao acordo de leniência, impondo-se, assim, o desentranhamento de todas as provas obtidas por meio da aplicação do instituto.

Outro fator que levaria a inconstitucionalidade da isenção penal concedida ao delator é que a titularidade da ação penal pública incondicionada, como é o caso dos crimes previstos na Lei 8.137/1990, é exclusiva do Ministério Público, competindo a este decidir acerca do cabimento da propositura da ação penal. A pacificação a respeito da constitucionalidade, ou não, do acordo de leniência caberá ao STF, guardião da Constituição, que, diga-se, até o presente momento não produziu nenhum precedente relacionado diretamente ao tema.

A despeito dos argumentos acerca da inconstitucionalidade do acordo de leniência, a sua aplicação colabora com a função do Estado, de interferir para conter o abuso ao poder econômico, beneficiando diretamente a sociedade justificando a sua aplicação em benefício da coletividade (MELLO; ROMANICHEN; ANDRADE, 2009, p. 14).

Outra questão que se levanta, diz respeito à revisão da decisão que concede o acordo de leniência pelo Poder Judiciário, posto que a Superintendência-Geral, órgão integrante do CADE, é responsável pela celebração do acordo de leniência, tratando-se, assim, de um órgão administrativo. No entanto, para examinar a revisão realizada pelo judiciário é necessário estabelecer algumas premissas referentes à decisão que concede o acordo, sob o ponto de vista de um ato administrativo.

Assim, insta salientar inicialmente, que as decisões do CADE são decisões administrativas, ou seja, além de preencher os requisitos descritos em lei, tem que atender aos requisitos do ato administrativo, como, sujeito, forma, objeto, motivo e finalidade. Sujeito é o autor do ato, aquele que tem legitimidade para praticá-lo; forma é um requisito externo do ato, como deve ser realizado; objeto é o que dispõe a lei, o que ela estabelece, esclarece Bandeira de Mello que o termo objeto não seria o mais apropriado e sim o termo conteúdo; motivo é a situação que enseja a realização do ato; finalidade, por sua vez, é o bem jurídico tutelado pela norma; e, por fim, "vontade é a disposição anímica de produzir o ato, ou, além disto, de atribuir-lhe um dado conteúdo" (MELLO, 2008. p. 384).

Os atos administrativos possuem diversas classificações, mas para a análise ora realizada é preciso considerar a classificação dos atos administrativos em discricionários ou vinculados.

Meirelles (2004, p. 165) ao discorrer sobre a classificação dos atos em discricionários ou 
vinculados assevera que atos vinculados são aqueles cuja lei estabelece requisitos e condições para sua realização. Dessa forma, o administrador fica limitado ao que a lei determina. Caso não atendidas as determinações legais a eficácia do ato fica comprometida, cabendo revisão da própria administração, ou pelo Judiciário. Quando se trata de um ato vinculado o administrado tem direito subjetivo de exigir a realização pela administração e caso the seja negado poderá recorrer ao Judiciário (DI PIETRO, 2005, p. 205).

Nos atos discricionários, por sua vez, a lei traça parâmetros, deixando margem para atuação da administração, ou seja, dentre várias soluções previstas em lei, poderá o Administrador optar por uma, utilizando-se dos critérios de oportunidade, conveniência, justiça e equidade para adotar a medida cabível. A discricionariedade deve ser pautada na lei, respeitando seus limites, caso ultrapasse-os, o ato torna-se arbitrário, podendo ter sua ilegalidade ou irregularidade declarada pelo Judiciário (DI PIETRO, 2005, p. 205). Para que seja legítimo o exercício da discricionariedade deve haver obediência não só a lei, como também aos princípios constitucionais da Administração Pública, tanto àqueles expressamente estabelecidos pela Constituição (legalidade, impessoalidade, moralidade, publicidade e eficiência), como aos que implicitamente fundamentam o ordenamento jurídico constitucional (GOMES, 2003, p. 100).

Saliente-se que tanto os atos vinculados como os discricionários, devem ser motivados, demonstrando que a sua prática está em conformidade com as exigências legais. Ou seja, o ato discricionário não deve ser arbitrário, permitindo-se ao administrador atuar com liberdade conformada pelo Direto, ou seja, a fonte da discricionariedade é a lei.

O artigo 199 do RICADE estabelece que preenchidos os requisitos previstos em lei, que foram descritos anteriormente, a Superintendência-Geral do CADE firmará o acordo de leniência. Da detida leitura do artigo citado verifica-se que a lei não deixa margem para atuação discricionária do CADE; a norma é completa. Trata-se de ato vinculado, devendo a lei ser interpretada objetivamente, caracterizando um direito subjetivo do agente econômico. Assim, a Superintendência-Geral do $\mathrm{CADE}$, ao receber a proposta do acordo de leniência, passará à verificação do preenchimento dos requisitos para concessão, cuja conformidade legal garante ao agente econômico a concretização do acordo e o gozo dos benefícios dele decorrentes (BRASIL, CADE, 2012, p. 62).

Estabelecida a premissa de que o ato do CADE que concede o acordo de leniência é um ato administrativo vinculado, passemos a análise quanto à possibilidade de revisão dessa decisão pelo Poder Judiciário.

A controvérsia relativa à revisão reside na complexidade técnica das decisões que são 
tomadas pela autarquia federal (CADE), pois o seu Tribunal é um órgão judicante, composto por membros especializados, entre eles juristas e economistas que analisam e decidem segundo bem estar social, tal como prescreve o artigo $1^{\circ}$, parágrafo único, da atual Lei Antitruste, cujos bens por ela tutelados tem por destinatário a coletividade.

A Administração, no exercício de suas funções, se sujeita ao controle exercido pelos Poderes Legislativo e Judiciário, sem prejuízo da autotutela. Esse controle tem por objetivo assegurar a atuação da Administração de acordo com os princípios que lhe são impostos, como o da moralidade, da finalidade pública, da publicidade, da impessoalidade e da motivação. (DI PIETRO, 2005, p. 636).

Conforme abordado acima o ato vinculado é inteiramente regulado por lei, assim como o ato discricionário, mas este último deixa margem para que o administrador possa aplicar a lei ao caso concreto, levando em contra critérios como a conveniência e oportunidade. Não obstante a margem de atuação conferida pela lei ao administrador, os atos discricionários também poderão ser submetidos ao controle judicial. De Luís Roberto Gomes (2003, p.99) se infere que se a discricionariedade for ilegítima, contrária às regras estabelecidas pelo povo, representado pelo Poder Legislativo, para atingir sua finalidade, qual seja, o interesse público, o ato será passível de intervenção.

Em razão das peculiaridades apontadas, o ato vinculado, em possível submissão ao Judiciário, será analisado somente sob o prisma da legalidade, da sua conformidade com a lei. 0 ato discricionário, por sua vez, deve ser analisado sob o aspecto da legalidade e do mérito, que nada mais é que a oportunidade e conveniência do ato perante o interesse público, desde que não invada os aspectos referentes à apreciação subjetiva (DI PIETRO, 2005, p. 654).

A legalidade administrativa está relacionada com a previsão do ato praticado em lei, ou seja, ao contrário da legalidade que rege as relações particulares, em que é permitido fazer tudo que a lei não proíbe, a legalidade administrativa estabelece que é defeso a realização de qualquer ato não previsto em lei. A moralidade está ligada com a ideia de bom administrador, não se norteando apenas pela legalidade, mas também as fronteiras entre o lícito e o ilícito, o justo e o injusto, o honesto e o desonesto. Devendo o administrador observar os padrões éticos. A autoridade administrativa deve se guiar pela probidade (MEIRELLES, 2004, p. 88).

A despeito da decisão no acordo de leniência ser uma decisão vinculada, as decisões do CADE são pautadas na discricionariedade técnica, em decorrência da especificidade da matéria tratada pelos seus membros (ROMAN 2013, p. 110).

O Ministro do STJ, Herman Benjamin (2010, p. 16-20), em voto proferido no Recurso 
Especial no 615.628 - DF (2003/0215979-3), destacou a especialidade das decisões do CADE e a cautela que o Judiciário deve ter na revisão de suas decisões. Dos órgãos da Justiça diz ser exigível cuidado e acatamento (o que não se confunde com covardia), pois os integrantes da autarquia são altamente especializados nas questões de direito da concorrência. Assim, não é razoável que o judiciário desconsidere as questões técnicas que constam dos autos, sob o argumento de que não há riscos ao mercado, sem uma análise e fundamentação pormenorizada sobre a controvérsia.

Assevera o Ministro que não há que se falar em não submissão das questões decididas pelo Tribunal do CADE à apreciação pelo Judiciário, posto que a Constituição Federal, em seu artigo 5ㅇ, inciso XXXV, traz o princípio da inafastabilidade da jurisdição. Sem prejuízo desse controle, aos juízes cumpre observar e dar a devida importância às decisões do CADE, porquanto órgão com conhecimento específico sobre as matérias por ele decididas. No entanto, as técnicas aplicadas ao controle da discricionariedade administrativa também devem ser aplicadas à discricionariedade técnica, como, por exemplo, a avaliação pelo Judiciário se a autoridade administrativa incorreu em abuso de poder na análise perpetrada (RONAN, 2013, p. 199).

Assim, em decorrência destas peculiaridades até que ponto a decisão do juiz monocrático poderia substituir a decisão do CADE? (FORTES, 2007, p. 4).

Quanto ao acordo de leniência, por se tratar de ato vinculado, como visto anteriormente, poderá ser controlado ou revisto de forma ampla pelo Judiciário. No entanto, sem perder de vista a especialidade empregada nos referidos atos, sob pena de ingerência de um Poder nas funções de outro. Deve-se ter em conta que o CADE é um órgão altamente especializado, já que lhe cumpre a análise do mercado e das situações que possam afetá-lo, o que exige visão específica e direcionada com o fim de proteger a livre iniciativa e a livre concorrência constitucionalmente garantidas. Portanto, se por um lado esse alto grau de especialidade das decisões proferidas pelo CADE não fasta o controle externo do Judiciário, por outro, a autoridade judiciária deve analisar a ocorrência de irregularidades decorrentes da ilegalidade ou imoralidade do ato, sendo-Ihe vedado invadir a seara técnica respeitante ao mercado e à concorrência, sempre fundamentando adequadamente a decisão para sujeita-la ao controle próprio de duplo grau de jurisdição.

\section{CONCLUSÃO}

Ao longo deste estudo, foram abordadas as discussões doutrinárias referentes ao acordo de leniência, e os argumentos favoráveis e contrários à aplicação do instituto. Não obstante as críticas, é preciso considerar que o acordo de leniência é uma forte arma no combate aos cartéis que, por sua vez, caracterizam a mais grave forma de lesão à livre concorrência, acarretando 
prejuízos aos consumidores e aos agentes econômicos não envolvidos na conduta ilícita, em decorrência do descontrole do mercado, afetando diretamente o bem-estar socioeconômico.

No entanto, os argumentos acerca da inconstitucionalidade do acordo de leniência são consistentes, mas não afastam sua aplicação que se fundamenta no princípio da livre concorrência, protegido constitucionalmente pelo artigo 170 , inciso IV.

O acordo de leniência é concedido por ato administrativo vinculado, nos exatos termos da lei. Além do mais, existe a possibilidade de apreciação dessa decisão pelo Judiciário em razão do princípio da unicidade da jurisdição. Uma possível revisão, no entanto, deve limitar-se ao controle da legalidade e da moralidade, devendo considerar que a atuação do CADE é altamente especializada nas questões concernentes ao direito concorrencial que foge do contexto das questões analisadas ordinariamente pelo Judiciário.

A aplicação do acordo de leniência se fundamenta em um bem maior: o combate aos cartéis, a proteção da ordem econômica, dos consumidores e dos demais agentes econômicos, prestigiando o bem-estar socioeconômico, o que embasa a aplicabilidade do instituto.

Pelos motivos declinados acima, evidencia-se que o acordo de leniência é uma arma indispensável para a proteção da livre concorrência e, especialmente, para o combate aos cartéis, que são cercados pelo mais absoluto sigilo, o que dificulta a obtenção de provas que embasem o início de um processo de responsabilização administrativa e penal. A aplicação do instituto tutela o equilíbrio do mercado e o direito a uma concorrência equilibrada, com preços competitivos, o que justifica a aplicação do instituto e as isenções por ele concedidas.

\section{REFERÊNCIAS}

BRASIL. C. N. Lei n 12.529 de 30 de novembro 2011. Estrutura o SBDC [...]. Diário Oficial da União, 01 de dez. de 2011.

BRASIL. CADE. Programa de leniência. Disponível em: <http://www.cade.gov.br/Default.aspx?a9898b959b7aba90a4a5ba>. Acesso em 14 fev. 2015.

BRASIL. CADE. Resolução no 1, de 29 de maio de 2012. Aprova o regimento interno do CADE RICADE. Diário Oficial da União, Brasília, DF, 31 maio 2012.

BRASIL. STJ. Administrativo. MS. Aplicação de multa pelo plenário do CADE. RE no 615.628 - DF (2003/0215979-3). Recorrente: CADE. Recorrido: General E. C. Relator: Ministro H. B., 08 de junho de 2010. Disponível em: <http://stj.jusbrasil.com.br/jurisprudencia/19099815/recurso-especialresp-615628-df-2003-0215979-3/inteiro-teor-19099816 > Acesso em: 25 mar. 2015.

DI PIETRO. M. S. Z. Direito Administrativo. 18oed. São Paulo: Atlas, 2005. 
FORTES, F. T.. A judicialização da defesa da concorrência. Revista do IBRAC - Direito da Concorrência, Consumo e Comércio Internacional. v. 15, p. 39-61, jan. 2007.

GABAN, E. M.; DOMINGUES, J. O. Direito antitruste: o combate aos cartéis, 3 ed. São Paulo: Saraiva, 2012.

GOMES, L. R. O ministério público e o controle da omissão administrativa: o controle da omissão estatal no direito ambiental. 1. ed. São Paulo: Forense Universitária, 2003.

LIMA, J. L. O.; ACQUA, R. D. A inconstitucionalidade do Acordo de Leniência. Disponível em: $<$ http://www.conjur.com.br/2007-jun-01/inconstitucionalidade_acordo_leniencia\#tauthor $>$. Acesso em: 01 abr. 2015.

MEIRELLES, H. L. Direito administrativo brasileiro. 29a ed. São Paulo: Malheiros, 2004.

MELLO, C. A. B. de M.. Curso de direito administrativo. 25a ed. São Paulo: Malheiros, 2008.

MELLO, S. S. F.; ROMANICHEN, M. M.; ANDRADE, A. B. Processo administrativo antitruste e antidumping: estudo comparativo do aspecto consensual no exercício da função administrativa no acordo de leniência e no compromisso de preços. Disponível em:

<http://www.revistas.ufg.br/index.php/revfd/article/view/9884/6758>. Acesso em 02 nov. 2014.

ROMAN, F. J. Discricionariedade técnica na regulação econômica. 1. ed. São Paulo: Saraiva: 2013. 